\title{
O político e sua tópica: divisão e unidade - identidade e representação. Ou sobre a dupla forma de polarização do espaço público
}

\author{
Political Topic: the Concepts of Division and Unity, \\ Identity and Representation as the Double Formal \\ Structure of Political Space
}

*João Carlos Brum Torres

\begin{abstract}
Resumo: O propósito do artigo é apresentar o conceito de 'tópica política' como o recurso teórico necessário para elucidação das determinações formais que estruturam as relações políticas em seu nível mais geral. A primeira seção do texto evoca os contextos doutrinários em que o conceito de tópica foi introduzido com intenções em alguma medida análogas às que animam o artigo, sendo brevemente considerados os usos do termo nas obras de Aristóteles, Kant e Freud. A segunda seção examina os conceitos de divisão e unidade, tratando de mostrar que as sociedades humanas são ao mesmo tempo necessariamente divididas e unificadas. Divididas na medida em que, como já mostrara Aristóteles e como o repetirá Tomás de Aquino, sendo a sociedade composta por uma multidão, o estatuto de sua unidade é necessariamente sui generis: ela não pode ser absolutamente una, pois, se o fosse, já não poderia ser uma cidade. Unificadas na medida em que as diferenças e distinções sociais, na medida em que adquirem caráter político, sobrevêm sempre dentro de uma sociedade, a unidade desta última tendo estatuto necessariamente reflexivo. A terceira seção introduz o exame dos conceitos de identidade e representação a partir da análise crítica da tese do jovem Marx de acordo com a qual a democracia é a verdade da monarquia mas a monarquia não é verdade da democracia. A seção prossegue com a retomada do exame destas noções a partir das análises de Carl Schmitt. A quarta e última seção do texto trata
\end{abstract}

\footnotetext{
* Coordenador do Curso de Mestrado em Filosofia da Universidade de Caxias do Sul. Professor Titular aposentado e Professor Colaborador da UFRGS. Pesquisador do CNPq. < brumtorres@ gmail.com>.
} 
de explicitar os ganhos críticos, heurísticos e metapolíticos que a introdução do conceito de tópica na teoria política pode proporcionar. Palavras-chave: Tópica. Identidade. Representação. Divisão. Unidade.

\begin{abstract}
The main proposal of this paper is to present the concept of the political topic as a theoretical device necessary to explain the more general and formal properties which constitute the framework of political relationships. The first section recalls other theoretical domains in which the concept of topic has been employed with objectives analogous to those pursued in the paper. The use of this concept by Aristotle, Kant and Freud is briefly considered. The second section deals with the concepts of division and unity, introduced as the first axis of political topic, and remarks that Aristotle and Aquinas long ago argued that the unity of human societies is necessarily limited since they are constitutively composed of multiple individuals. Moreover, they underlined such unity is necessarily sui generis and limited, because if the polis were absolutely unified its societal character would vanish. But human societies are also unified and their unity delimits the political space in which social differences supervene. The closing part of the section claims that the peculiar unity of human societies must be recognized as being necessarily reflexive. The third section presents the concepts of identity and representation. It starts by critically analyzing the young Marx' thesis according to which democracy is the truth of monarchy but monarchy is not the truth of democracy. The text continues, surveying Carl Schmitt's treatment of these concepts in order to demonstrate the sense in which they must be viewed: as the poles of the second axis of the political topic. The fourth and last section of the paper emphasizes the critical, heuristic and meta-political gains provided by the concept of political topic.
\end{abstract}

Keywords: Topic. Identity. Representation. Division. Unity.

\title{
1 Preliminares
}

Para inicialmente esclarecer o sentido em que tomarei a palavra tópica, observo que não foi a tradição da filosofia política que me induziu a ela recorrer, pois tal termo não faz parte, pelo menos não explicitamente, do multimilenarmente constituído acervo conceitual da disciplina. Foram antecedentes encontráveis em bem outras paragens do universo filosófico que me fizeram pensar que tópica poderia ser útil para designar certas propriedades formais do espaço político. Dentre esses antecedentes mais ou menos remotos, primeiramente pensei nos Tópicos de Aristóteles; em seguida tive em mente o sentido muito específico que Kant deu à tópica na Nota sobre a anfibologia dos conceitos de reflexão; em terceiro lugar, enfim, lembrei-me da acepção adquirida pela palavra no contexto da obra freudiana. No primeiro caso, do espectro de variações semânticas admitidas pelo termo, importou-me menos o sentido próprio - que, como sabido, designa o modo como os quatro tipos fundamentais de predicação 
(definição, propriedade, gênero e acidente) aparecem em diferentes contextos argumentativos -, do que a definição dada por Teofrasto ao termo cognato tópico, consoante a qual este "é o elemento do qual tomamos os pontos de partida concernentes a cada matéria", elemento que "é delimitado em sua abrangência, mas ilimitado quanto ao número de coisas que caem sobre ele." Já do conceito de tópica transcendental, interessou-me a indicação de que os assim chamados quatro títulos de toda comparação das representações (identidade e diversidade, concordância e oposição, interno e externo, matéria e forma) precisam ter seu emprego orientado pela atenção aos lugares de proveniência dos materiais a serem cotejados. ${ }^{2}$ Quanto, enfim, à pista vinda de Freud, o aspecto que me chamou atenção foi o do apelo à metáfora espacial para designar não só a diferenciação e a autonomização funcional de instâncias do psiquismo humano, mas também a ideia de que o funcionamento de tais instâncias tem relações dinâmicas polarizadas, seja no âmbito da chamada primeira tópica (inconsciente, pré-consciente, consciente), seja no da segunda, a que extrema Id, Ego e Superego.

Todavia, convém desde logo enfatizar que os pares conceituais mencionados no título deste texto - identidade e representação e unidade e divisão - não são equivalentes a nenhum dos elementos constituintes das tópicas aristotélica, kantiana ou freudiana, pois não são eles nem esquemas proposicionais, como se pode entender que o sejam os topoi de Aristóteles; nem ferramentas conceituais para formação de conceitos, como no caso kantiano, assim como tampouco são designadores de sistemas dinâmico-funcionais geradores de representações e de atos psíquicos, como são os elementos que ocupam as posições nas tópicas freudianas. Bem distintamente, os termos que integram a tópica política fazem referência é às posições polares que constituem o domínio do político, para empregar a expressão em cujo uso os autores da filosofia política francesa do último quartel do século XX, na esteira de Carl Schmitt, se comprouveram. O que é dizer que identidade e representação e unidade e divisão devem ser entendidos como os componentes fundamentais da estrutura formal do político, entendida a palavra como designadora da dimensão da vida das comunidades humanas na qual ganha forma, se desdobra e transcorre a política no sentido usual do termo.

Apud Alexander of Aphrodisias, On Aristotle Topics 1, Bloomsbury Academics, New York, 2014, p. 7. (originalmente publicado por Duckworth, Londres, 2001). Cf. in Aristóteles, Tópicos, Centro de Filosofia da Universidade de Lisboa e Imprensa Nacional - Casa da Moeda, Lisboa, 2007, a excelente Introdução de J. A. Segurado Campos, notadamente, para o texto citado: p. 110 , nota 187.

2 V. Immanuel Kant, Crítica da Razão Pura, A 269|B 325. Na tradução de Manuela Pinto dos Santos e Alfredo Frdique Morujão, publicada pela Fundação Calouste Gulbenkian, Lisboa, 1989, p. 279. 
A despeito desse sentido muito específico dado aqui à palavra tópica, alguma afinidade com as acepções que lhe foram assignadas nos âmbitos doutrinários acima mencionados não é difícil de ser percebida. Primeiramente, se repararmos que identidade e representação, unidade e divisão, analogamente aos topoi aristotélicos, ao identificarem certas coordenadas formais, não, é claro, dos esquemas proposicionais, mas do espaço político, permitem entender de que modo as quase ilimitadas variações das relações políticas reais se enquadram dentro de certos limites que, ao restringi-las, funcionam como princípios estruturantes; em segundo lugar, se notarmos que tais conceitos, semelhantemente aos pares da tópica transcendental, são também instrumentos necessários para a formação das figuras institucionais em função e ao redor das quais se organiza a vida política concreta; enfim, uma terceira linha de afinidade pode ser identificada se e quando nos dermos conta que, tal como os loci das tópicas freudianas, as posições formalmente polares do espaço político não são inertes, mas antes providas de uma espécie de força.

É indiscutível, porém, que o esclarecimento do sentido do que estou propondo denominar de tópica politica não pode ser feito por meio das comparações crípticas e alusivas que acabei de fazer e o objeto deste artigo é justamente o de tratar desses diferentes pontos de maneira mais analítica.

\section{Divisão e unidade}

Carl Schmitt introduz o sentido político do conceito de unidade como nota determinante do que denomina de conceito absoluto de constituição - isto é, de constituição como sinônimo de Estado, em passo análogo ao dado por Aristóteles na Política ${ }^{3}$ - simplesmente fazendo notar que não há polis sem constituição, assim como não há constituição senão como constituição de uma polis. O que é sustentar que não faz sentido falar de Estado senão implicando que o termo faz referência ao modo como uma pluralidade de indivíduos, famílias e grupos sociais se unifica e, desse modo, constitui uma comunidade. ${ }^{4}$

3 Na Política lê-se que a "comunidade é estabelecida graças a constituição [...]". In: Aristóteles, Política, L. II, cap. 2, 1277a. Na tradução de Mário da Gama Cury, Editora da Universidade de Brasília, 1985, p. 83.

4 Ao apresentar o que denomina de conceito absoluto de constituição, Carl Schmitt apresenta o conceito de unidade política dizendo: "A todo Estado corresponde: unidade política e ordenação social. Pode-se denominar constituição essa estrutura global da unidade política e da ordem social." V. Carl Schmitt, Teoria da Constituição, § 1; na tradução espanhola de Francisco Ayala (1934), reeditada por Editora Nacional, Mexico, D. F., 1981, p. 4. Por óbvio, a palavra constituição neste contexto não designa uma carta contendo os princípios jurídicos de organização dos poderes, o rol de direitos constitucionalmente assegurados, etc. 
No entanto, é necessário desde logo apontar que, como já mostrara Aristóteles e como o repetirá Tomás de Aquino, que sendo a sociedade composta por uma multidão, o estatuto de sua unidade é necessariamente sui generis: ela não pode ser absolutamente una, pois, se o fosse, já não poderia ser uma cidade. É o que explica a seguinte passagem da Política:

[...] a cidade é por natureza uma pluralidade; se sua unificação avançar demasiadamente, a cidade será reduzida a uma família, e a família a um indivíduo, pois podemos dizer que a família é mais una que a cidade e o indivíduo mais uno que a família; logo, mesmo que alguém fosse capaz de unificar a cidade, ele não deveria fazê-lo, pois com isso destruiria a cidade. A cidade não é constituída somente de uma pluralidade de seres humanos, mas de seres humanos de diversas condições. ${ }^{5}$

Repare-se que a constitutiva diversidade da cidade é determinada e subdividida em vários planos: seja como a diversidade implicada pela divisão social do trabalho ou pela distinção dos gêneros, seja como a diferença política entre governantes e governados, seja, para os antigos, hoje inaceitavelmente, como a diferença de estado, própria da divisão entre cidadãos, homens livres por natureza, e escravos. A esse espectro de divisões, é necessário acrescentar ainda os antagonismos provenientes do modo como a forma específica assumida pela divisão social do trabalho distingue hierarquicamente classes e categorias sociais e distribui os indivíduos entre elas. Este, aliás, é o ponto sobre o qual Marx, muito especialmente, insistiu. ${ }^{6}$ De outra parte, porém, convém muito enfaticamente sublinhar que quando essas diferentes formas de divisão social são consideradas concretamente salta aos olhos que

5 Cf. Política, 1261b, ed. cit., p. 36. Santo Tomás parafraseia o texto dizendo: "Foi dito acima que a cidade é uma espécie de multidão e multidão se opõe a unidade. De onde que se a cidade fosse mais una do que deveria, já não seria cidade. [...] Sendo assim, se alguém pudesse fazer com que em toda cidade houvesse tanta unidade como há em uma casa de família, não deveria fazê-lo, pois isso a destruiria. Mas porque alguém poderia dizer que Sócrates não tinha em mente uma unidade que excluisse a pluralidade das pessoas, mas a que excluísse as diferenças entre elas, deve-se sustentar da mesma forma que a cidade não deve ser feita de homens que sejam totalmente semelhantes, mas de homens de diversas condições. [...] nas coisas naturais descobre-se que os todos perfeitos são constituídos de partes diversas, como o homem de carne, ossos e nervos. Assim é manifesto que, como a cidade é de algum modo um todo perfeito, convém que seja ela composta de partes dessemelhantes segundo a espécie." Tomas de Aquino, Sententia libri Politicorum, Livro 2, lectio 1, notas 11 e 12. $<$ http://www.corpusthomisticum.org/cpo.html>.

6 V. Karl Marx e Friedrich Engels, Manifesto Comunista, São Paulo: Boitempo Editorial, 1998, p. 40, onde se lê: "A história de todas as sociedades até hoje existentes é a história das lutas de classes. Homem livre e escravo, patrício e plebeu, senhor feudal e servo, mestre de corporação e companheiro, em resumo opressores e oprimidos em constante oposição, têm vivido numa guerra ininterrupta, ora franca, ora disfarçada [...]. A sociedade burguesa moderna [...] não aboliu os antagonismos de classe. Não fez mais do que estabelecer novas classes, novas condições de opressão [...]." 
elas se manifestam primariamente como divisões dentro de sociedades determinadas, em um espaço já delimitado politicamente - sempre já no interior da cidade, para continuar com a terminologia clássica, ou dentro dos países, como se tenderia hoje a dizer. Essa constatação faz imediatamente ver que tais divisões são sobredeterminadas e, mais especificamente, que são divisões que pressupõem a unidade formal do espaço político em cujo âmbito sobrevém e que é isso que pode lhes conferir status político . O que é dizer que o espaço político não pode ser considerado como derivado da forma como se estruturam as divisões internas às sociedades, inclusive não, como pretendido pela teoria marxista, como um efeito da "forma específica pela qual é extorquido o sobretrabalho", a qual, alegadamente, determinaria em última instância "a estrutura política específica da comunidade". ${ }^{7} \mathrm{E}$ isso pela razão simples de que as formas específicas de extorsão do sobretrabalho não são elas próprias politicamente incondicionadas. O que é dizer que a forma política não pode ser vista como determinada em termos fundamental e redutoramente funcionais, como se sua razão de ser fosse unicamente a de dar uma resposta ao problema de determinar um ou outro modo de viabilização institucional da extorsão do sobretrabalho. Ademais de que o largo espectro de outras questões sociais com relação às quais a forma política cumpre um papel determinante exclua a possibilidade de uma tal redução, é preciso reconhecer que é a própria abertura da série de possíveis formas de extorsão do sobretrabalho que é politicamente ao mesmo tempo aberta e determinada. Politicamente aberta no sentido em que os termos em que são estruturadas as relações de produção já estão sempre inseridos e são sempre condicionados por um contexto social, político e ideológico cuja variação histórica é irredutível a qualquer determinismo. Politicamente determinada, porém, no sentido de que toda e qualquer forma de estruturação de relações de produção só pode ser estabelecida dentro de um tal quadro político-institucional antecedente, por mais simples e primitivo que seja este. ${ }^{8}$

Pode-se, é claro, tentar determinar essa unidade pressuposta vinculando-a a determinantes pré-políticos, como a ocupação de uma área geograficamente circunscrita por uma certa população; ou como a homogeneidade étnica que esta última eventualmente possua; ou como o compartilhamento de uma mesma religião e/ou de uma mesma

7 Cf. Karl Marx, O Capital, L. III, Gênese da renda fundiária capitalista, na edição de Maximilien Rubel, Oeuvres, Économie II, Gallimard, Paris, 1968, p. 1400.

8 O exame mais profundo dessa problemática, cuja apresentação é impossível de ser feita aqui, foi realizado por Castoriadis, notadamente em L'institution imaginaire de la société, Seuil, Paris, 1975. Embora esse seja um tema que permeia todo o livro, confira-se, mais imediatamente, o capítulo III. 
língua; ou, como recém visto, como o modo como se organizam as relações de produção, ou ainda, enfim, como a combinação desses diferentes fatores pelos agregados populacionais que se considerar. No entanto, é quase intuitivo o reconhecimento de que fatores geográficos, socioeconômicos, étnicos, linguísticos ou religiosos não são condições suficientes para formação de uma cidade, assim como é certamente falso que sua acumulação aditiva seja sequer uma condição necessária para tanto. Todavia, não é muito claro porque isso é assim e convém que nos detenhamos sobre o ponto.

Para antecipar o que precisa ser mostrado, o que creio deva ser reconhecido é que a constituição de todos humanos socialmente unificados só pode ter lugar politica e reflexivamente.

Demonstrar essa alegação é, contudo, tarefa complexa. Para sua elucidação um bom ponto de partida pode ser a lição de Hobbes no $\S 5$ do capítulo V do De Cive, intitulado Das causas e da origem primeira do Governo Civil. Nessa passagem o filósofo compara o estatuto das sociedades humanas com o que caracteriza a condição social de outros animais, daqueles que já Aristóteles reconhecia e dizia políticos, e então afirma:

Aristóteles inclui entre os animais a quem chama políticos, não apenas o homem mas diversos outros - como a formiga, a abelha, etc. que, embora careçam de razão, pela qual poderiam contratar e submeterse ao governo, não obstante consentem; isto é, perseguindo ou fugindo das mesmas coisas, dirigem de tal modo seus atos para um bem comum que sua reunião não está sujeita a nenhum tipo de sedição. Mas apesar disso tal reunião não constitui um governo civil, e portanto tais animais não podem ser denominados políticos, porque seu governo consiste apenas no consentimento, ou seja, em muitas vontades concorrendo para o mesmo objetivo, não sendo - o que é necessário no governo civil uma vontade única.

Bem entendido, à primeira vista pode-se pensar que esse texto não só nos distrai, por não manter o foco na questão da unidade, mas que, além disso, é patentemente circular. Com efeito, Hobbes parece estar clamorosamente begging the question, como se costuma dizer em inglês, pois conquanto reconheça que os múltiplos membros dessas colônias de insetos concorram para a vida e para o bem da comunidade, ele alega que tais bestiolas não formam uma verdadeira unidade política "porque seu governo consiste apenas no consentimento, ou seja, em muitas vontades concorrendo para o mesmo objetivo, não sendo - o que é necessário no governo civil - uma vontade única." Ora, essa alegação parece reduzir-se a sustentar que esses insetos não podem ser ditos políticos porque, 
não tendo sobre si um governo civil, não têm sua unidade fundada naquilo que definicionalmente constitui, para Hobbes, o político, a saber: a instituição de um Governo Civil. Contudo, essa interpretação impressionista não capta o modo como a análise hobbesiana demonstra a necessidade de pensar mais aprofundadamente as condições e a forma, ambas irredutivelmente únicas, da unidade dos coletivos humanos. A chave para alcançar essa melhor compreensão está em levar na devida conta a oposição feita no texto entre muitas vontades concorrerem para um mesmo objetivo e haver, de todas, uma única vontade. No Capítulo II do Leviatã, Hobbes explica o alcance dessa distinção dizendo

[...] ser impossível distinguir sem estudo e grande entendimento entre uma ação de muitos homens e muitas ações de uma multidão, como por exemplo entre a ação única de todos os senadores de Roma ao matarem Catilina, e as muitas ações de certo número de senadores ao matarem César. Fica-se portanto [equivocadamente] predisposto para tomar como do povo aquilo que é uma multidão de ações praticadas por uma multidão de pessoas. ${ }^{9}$

A tese de Hobbes, entenda-se, é que nem a simples interação entre agentes independentes como se tem, por exemplo, no funcionamento dos mercados, nem mesmo o comportamento espontaneamente cooperativo de vários agentes são suficientes para conferir unidade a uma multidão humana, pois as muitas ações dos indivíduos que a integram, mesmo quando entre si interativas e mesmo cooperativas, não deixam de serem ações dispersas, ações de uma pluralidade de indivíduos que, não por isso, se têm como partes de uma unidade e que neste plano só podem ser considerados como reunidos de um ponto de vista exterior e nominalista, ao modo como quando, por exemplo, formamos conjuntos pela eleição mais ou menos discricionária de uma propriedade que seja compartilhada por vários itens.

Ora, se isso é verdade, segue-se que a unidade dos conjuntos humanos terá que ser necessariamente reflexionante. Reflexionante na razão e na medida em que sua constituição depende de que os indivíduos que as integrem reconheçam seu pertencimento a uma certa e determinada comunidade. Pouco importa que ordinariamente esse reconhecimento seja meramente passivo e disposicional e que sua manifestação explícita, discursiva e generalizada só ocorra em circunstâncias críticas, como quando, internamente, há disputa agônica sobre quem pode legitimamente falar e agir em nome de todos, ou

Thomas Hobbes, Leviatã, São Paulo: Abril Cultural, 1974, p. 67. 
quando, na frente externa, a comunidade é confrontada com suas rivais, como ocorre paradigmaticamente no caso das guerras.

O ponto mais importante na análise dessa questão está, contudo, em entender que conquanto esse reconhecimento seja o elemento constitutivo da unidade política, ele é necessariamente um re-conhecimento, isto é, sua efetuação necessariamente apresenta-se como erguida sobre e sustentada por uma comunidade pré-existente e nunca como a geração ab ovo da sociedade. Uma boa ilustração do que estou querendo dizer se encontra nos termos em que se estruturam os atos de fundação constitucional formal e explícita. O exemplo mais conspícuo provavelmente se encontre na Declaração de Independência dos Estados Unidos. Com efeito, na passagem decisiva da Declaração lê-se:

Portanto, Nós os representantes dos Estados Unidos da América, reunidos em Assembléia Geral, em nome e pela autoridade do bom povo destas colônias [...] afirmamos e declaramos solenemente: que estas Colônias unidas são e por direito devem ser Estados livres e independentes $[\ldots]^{10}$

Este enunciado diz que as Colônias unidas são Estados livres e independentes, no entanto é evidente que foi a declaração conjunta de independência formada neste ato que fundou e, nesse sentido, produziu os Estados Unidos. Essa dupla determinação, creio que se pode dizer lógica, da Declaração põe em evidência exemplarmente como a relação entre, por um lado, diversidade e divisão e, por outro, união não deve ser vista simplesmente como uma relação de antecedência e consequência temporal, ainda que seja verdadeiro que antes da Declaração de Independência havia diversas colônias e que sua unificação só tenha ocorrido com a Declaração de Independência, muito precisamente no dia 4 de julho de 1776. ${ }^{11}$ Mas como assim? Como se pode entender que a

10 V. Carl L. Becker, The Declaration of Independence, Random House - A Vintage Book, New York, 1958 e Pauline Meyer, American Scripture - Making the Declaration of Independence, Alfred A. Knopf, New Yoik 1997.

$11 \mathrm{O}$ ato de declaração de independência dos Estados Unidos foi isolado aqui para fins de análise. Embora decisivo, ele foi o primeiro momento de um processo de institucionalização bastante complexo. Esse passo inicial foi logo seguido por vários outros. Primeiramente, pela aprovação pelo Congresso Continental, em 15 de novembro de 1777, dos 'Articles of de Confederation', seguida do longo processo de sua ratificação por cada uma das Colônias Unidas, cuja conclusão só veio a ocorrer em $1^{\circ}$ de março de 1781 . Todavia, a forma final dada à instituição do novo Estado só veio a ser produzida bem posteriormente. O que talvez se possa chamar de segunda fase da estruturação do poder e das instituições políticas americanas teve início com a convocação da Convenção Constitucional, reunida na cidade de Philadelphia em maio de 1787, cujo momento maior foi a aprovação, em 17 de setembro de 1787, do texto da Constituição dos Estados Unidos, aprovação, ela também, seguida, de longo procedimento ratificatório só terminado em 29 de maio de 1790, com a última das ratificações: a do Estado de Rhode Island. 
unidade não seja simples e univocamente posterior à divisão das Colônias antes do dia 4 de julho?

Para responder a esta pergunta será útil recuperar uma análise de Merleau-Ponty cuja relevância para o entendimento da estrutura profunda das formas políticas foi notada, há já mais de quarenta anos, por Lefort e Gauchet. ${ }^{12} \mathrm{O}$ interesse de Merleau-Ponty no texto para o qual chamam atenção os comentadores mencionados era mostrar a inelutabilidade de certo movimento de reenvio recíproco e circular que a filosofia encontra na determinação do estatuto de vários de seus principais objetos de análise, fenômeno que o texto ilustra variadamente, por exemplo mediante o registro de que os filósofos se veem inapelavelmente obrigados a simultaneamente sustentar não só que "o ser é" e que "as aparências não são senão manifestações e restrições dele", mas também que essas mesmas aparências "são o canon de tudo o que podemos entender por 'ser' ", de modo que neste segundo caso "é o ser que aparece como a figura de um fantasma inapreensível e de Unding". Dessa análise nos importa a conclusão geral, que Merleau-Ponty apresenta assim:

o vai e vem das filosofias entre uma e outra dessas perspectivas não seria contradição no sentido de inadvertência ou incoerência, mas seria fundado no ser. [...] A tarefa da filosofia seria a de descrever, de elaborar um conceito do ser no qual as contradições, nem aceitas, nem 'ultrapassadas' encontrariam seu lugar. [...] O que as filosofias dialéticas não conseguiram fazer [...] tornar-se-ia possível para uma ontologia que descobrisse no próprio ser uma instabilidade ou um movimento. ${ }^{13}$

Ora, é precisamente essa instabilidade ou movimento presente no próprio ser, como diz o texto, que encontramos no par conceitual unidade/ divisão-diversidade, ou, mais exatamente, no reenvio reciproco e, sob esse aspecto, circular que nos vemos compelidos a reconhecer presente na articulação desses termos quando tratamos de determinar mais precisamente o estatuto das entidades políticas. Como vimos acima, o modo de ser dos objetos políticos envolve a formação de todos unitários, vale dizer: a superação das dispersões dos seres humanos e a formação de uma unidade. No entanto, essa unidade não pode ser concebida como o efeito simples de uma decisão de formação de unidade, mas supõe e implica expressamente que essa unidade é já um fato, uma realidade cujo estatuto real é independente de e antecedente ao ato declaratório. Em um

12 V. Claude Lefort e Marcel Gauchet, Sur la démocratie: le politique et l'institution do social, in Textures, 1971, n. 2-3. O artigo foi redigido por Gauchet com base em um curso dado por Claude Lefort na Universidade de Caen em 1966-1967.

13 V. Maurice Merleau-Ponty, Resumés de Cours - 1952-1960, Gallimard, Paris, 1968, p. 127. 
texto dedicado à análise dos atos de discurso que efetuam a constituição de ordens política novas, tive ocasião de assinalar:

[...] os atos de fundação política são compostos pelas declarações fundadoras [...] e pela exibição do título que alegadamente autoriza a sua execução, designando esse segundo termo o ato discursivo complementar graças ao qual é introduzido o sujeito do ato principal. ${ }^{14}$

No presente contexto, porém, o que me interessa acentuar é que essa estrutura complexa dos atos declaratórios - que envolvem sempre uma cláusula destinada a fazer deles simplesmente a expressão discursiva de algo que, a despeito de que gerado pelo ato declaratório, é dito antecedê-lo e legitimá-lo - não deve ser vista como uma mera manobra retórica, que com frequência aparece nas circunstâncias em que é formada uma nova unidade política. Bem ao contrário, creio que antes e muito mais fundamentalmente ela precisa ser entendida como uma característica, como uma propriedade constitutiva do modo de ser das entidades políticas. Para continuar com o mesmo exemplo, é claro que, formalmente, as Colônias só se unificaram com a criação dos Estados Unidos, mas a formação da União não pode ser considerada meramente como um efeito, como uma consequência da declaração, pois para que a declaração produzisse esse efeito unificador foi necessário, antes de mais, que seu destinatário interno, o multifário povo das Colônias, aceitasse a União, se reconhecesse como formando esse conjunto unificado. E esse reconhecimento não pode ser razoavelmente entendido como resultado demiúrgico da declaração, mas implica antes que aqueles em nome dos quais elas foi feita se vissem e reconhecessem como efetivamente pertencentes a essa União que então se declarava. É evidente, portanto, que neste caso no vemos frente à instabilidade lógica da situação em pauta, frente ao movimento circular, de que falava Merleau-Ponty, que faz a união ao mesmo tempo dependente da Declaração e condição desta última. Importa ainda assinalar que essa mesma relação circular ocorre independentemente de que os atos de constituição da nova entidade política envolvam declarações explícitas, como a de nosso exemplo, pois mesmo quando a unidade política está baseada em um ato de força é claro que a união resultante da imposição da vontade soberana só se aperfeiçoa e se faz efetivamente soberana sob a condição de que os membros da multidão desunida aceitem submeter-se e reconheçam nessa vontade

14 V. João Carlos Brum Torres, Actes fondateurs au domaine politique, Les Cahiers de Fontenay, n. 67/68, E.N.S. Fontenay/Saint-Cloud, septembre 1992, p. 25. 
nova a expressão de sua união, a despeito de que in pectore a possam julgar intolerável.

É preciso entender também que esse assentimento e a constituição da unidade social não implica a dissolução das diferenças e divisões no seio do povo - diferenças de gênero, de geração, de status social, de crenças, de origem regional ou étnicas, de riqueza e classe - mas simplesmente requer que a aceitação de que antes e além de tais diferenças há uma unidade em cujo âmbito tais divisões e antagonismos estão enquadrados. Sem esta pressuposição de unidade tem-se ou a dispersão dos grupos humanos ou guerras, as quais, no sentido estrito do termo, não são conflitos políticos, pois são extra polis e almejam resolver diferendos e conflitos simplesmente pela imposição bruta da vontade do vencedor. $O$ que estou querendo dizer é que para que as divisões e conflitos sejam verdadeiramente políticos é necessário que eles sejam entendidos como divisões e conflitos internos, envolvendo uma decisão relativa ao modo como devem ser estruturadas as relações dentro de um espaço político em que os atores em antagonismo se encontram e se sabem inserto.s. ${ }^{15}$

Essa é razão que nos autoriza a ter unidade e divisão como elementos constituintes de uma tópica da política, como os polos formalmente antagonizados que ao mesmo tempo delimitam e estruturam o espaço das variações político-institucionais reais e que, assim, delimitam o espaço no interior do qual o perfil próprio de toda e qualquer entidade política é determinado. Neste sentido deve-se dizer que todas as contradições verdadeiramente políticas são contradições no seio do povo. Esta fórmula de Mao Tse Tung devendo-se entender, porém, não apenas no sentido de que as divisões e antagonismos sobrevêm em meio de uma população que compartilha relações econômico-sociais, um mesmo território, eventualmente uma mesma religião e uma mesma língua, mas mais essencialmente no sentido de que seus antagonismos são sempre inelutavelmente uma proposta de mudança nos termos da união.

Dir-se-á que as lutas de independência e que os movimentos secessionistas são um desmentido óbvio do que estou sugerindo, mas creio que a objeção erra o alvo, pois o que tais movimentos fazem é simplesmente propor o deslocamento da posição do traço de união, da linha que delimita o comum, de modo que, antes que desmentir-me, essa alegação confirma a tese que estou defendendo. A independência,

$\overline{15}$ Essa tese implica que a política externa, ou internacional, só é verdadeiramente política derivada e consecutivamente, além de que determinada pela medida em que seu traço constitutivo - a independência dos sujeitos políticos nela envolvidos, cuja interação lhe dá forma e conteúdo - tem necessariamente como horizonte sua questionabilidade, vale dizer: a possibilidade de eliminação de unidades políticas pré-existentes e de ampliação ou mesmo formação de novas entidades políticas. 
em qualquer de suas formas, inclusive a secessionista, ao tratar de unificar suas forças por meio da oposição ao outro todo do qual se pretende a separação - forças obviamente diversas e estratificadas, como necessariamente ocorre em qualquer conjunto social -, simplesmente leva ao ponto extremo e torna explícito o reenvio da divisão à unidade. Sua razão de ser é justamente que há uma outra união que precisa ser reconhecida.

Outra objeção, esta quem sabe mais forte, pode tentar apoiar-se nos casos em que se pretenda fazer da homogeneidade étnica, ou da origem regional, fatores de unificação social alheios à política. Mas também nesse caso é evidente que essa remissão a tais bases antepolíticas, se assim posso dizer, não é senão a contraface de um movimento de unificação que só terá êxito se seus atos conclamatórios e convocatórios do ativismo étnico ou regionalista, ao serem reconhecidos e ouvidos por aqueles a quem são endereçados, engendrarem um movimento político cujo desfecho venha a ser a criação de uma nova forma política. O que é dizer que tais movimentos só virão a constituir uma sociedade - polis ou país, conforme se queira chamar - se a multidão que lhe forma a base vier a ser unificada, já não mais étnica e regionalmente, mas politicamente.

\section{Identidade e representação}

Para apresentar o segundo eixo de estruturação do que estou propondo denominar tópica política, creio que o melhor ponto de partida será atentar para uma declaração de Marx no chamado Manuscrito de Kreuznach, que, aliás, já tive a ocasião de comentar em outros textos, e que diz:

A democracia é a verdade da monarquia; a monarquia não é a verdade da democracia. ${ }^{16}$

Como preliminar para elucidação dessa afirmação enigmática, sublinhe-se, antes de mais, que a expressão 'ser a verdade de' deve ser entendida de acordo com o conceito hegeliano de verdade, de acordo com o qual "São verdadeiros objetos quando esses são o que devem ser, isto é, quando sua realidade corresponde a seu conceito." 17 À luz dessa concepção ao mesmo tempo ontologizante e normativa da verdade, a tese de Marx é, portanto, a de que a monarquia só será verdadeira se for

16 V. Karl Marx, Crítica da filosofia do direito de Hegel, São Paulo: Botempo Editorial, 2005, p. 49.

17 V. G. W. F. Hegel, Enciclopédia das Ciências Filosóficas em Compêndio, I, § 213, Adendo. São Paulo: Loyola, 1995, p. 349. 
de algum modo democracia, ao passo que, em contraste, a democracia não poderá ser verdadeiramente democracia se de algum modo for monarquia. Essa glosa meramente formal não nos adianta grande coisa e algo mais produtivo talvez seja dizer que a democracia é a verdade da monarquia porque a representação monárquica pressupõe o povo do qual ela é, precisamente, a representação, enquanto que a monarquia não é a verdade da democracia porque o povo não pressupõe a existência de instituições representativas para existir. ${ }^{18} \mathrm{O}$ ponto ficará mais claro se lembrarmos de que nessas passagens Marx está criticando a Hegel e mais especificamente a tese hegeliana de que:

[...] a soberania existe enquanto personalidade do todo e esta existe na realidade conformada a seu conceito, isto é, enquanto ela é a pessoa do monarca." 19

A crítica de Marx é que, se fosse assim, se a soberania só existisse na pessoa do príncipe, então também "nas relações exteriores" ele, "mesmo sem o povo, poderia ser considerado como um Estado independente" ${ }^{20}$, o que é manifestamente um non-sense cuja implicação é mostrar que um soberano só poderá efetivamente constituir-se como tal se e enquanto representante e símbolo da unidade e da soberania populares. ${ }^{21}$ Muito mais problemática, porém, é a tese inversa, pois a negação de que a monarquia seja a verdade da democracia implica a ideia que onde houver representação soberana não haverá democracia. No texto que comentamos, o que Marx diz é que:

A monarquia não se pode compreender por ela própria, a democracia sim. Na democracia nenhum dos elementos que a constituem pode adquirir uma significação diversa da que lhe é própria. Cada um efetivamente é apenas um elemento do todo do Demos. Na monarquia uma parte determina o caráter do todo. ${ }^{22}$

18 Retomamos aqui análises feitas em Identidade e Representação - Notas Para uma Crítica dos Ideais Emancipatórios da Democracia Contemporânea, in Revista Filosofia Política 3, L\&PM, Porto Alegre, 1986.

19 V. G. W. F. Hegel, Linhas Fundamentais da Filosofia do Direito ou Direito Natural e Ciência do Estado no traçado fundamental, O Estado, trad. de Marcos Lutz Müller, IFCH/UNICAMP, 1998, p. 81. Na passagem citada, seguimos, no entanto, a lição de Dérathé e Frick que vertem o 'ist' do original como existe. Cf. Principes de la Philosophie du Droit ou Droit Naturel et Science de l'État en Abrégé. Paris: Vrin, 1975, ver § 279, p. 292.

20 In Karl Marx, Crítica da Filosofia do Direito de Hegel, São Paulo: Boitempo, 2005, p. 48.

21 Id. ib.

22 Id, p. 49, trad. ligeiramente modificada, de acordo com a lição de Kostas Papaioannou, in Karl Marx, Critique de l'État hégélien, UGE, 10/18, Paris, 1976, p. 105. 
Os pontos cruciais da passagem são a afirmação de que a democracia pode se compreender por ela própria e a cláusula que explicita o que seja essa compreensibilidade intrínseca: a afirmação de que na democracia nenhum dos elementos que a constituem pode adquirir uma significação diversa da que lhe é própria. Em vista da obscuridade dessas fórmulas, é preciso esclarecer o que seja essa intransitividade de significado que Marx sustenta ser própria da democracia. O próprio texto que comentamos explica melhor o ponto ao dizer:

Na democracia o princípio formal é ao mesmo tempo o princípio material. Por isso ela é [...] a verdadeira unidade do universal e do particular. [...] Na democracia também o Estado político se coloca ao lado desse conteúdo e se distingue dele, mas ele não é senão um conteúdo particular, enquanto forma de existência particular do povo. Na monarquia, por exemplo, este fato particular, a Constituição política tem a significação do universal que domina e determina todo particular. Na democracia o Estado, como particular, é apenas particular; como universal, é o universal real ${ }^{23}$, ou seja, não é uma determinidade em contraste como os outros conteúdos. Os franceses modernos concluíram daí que na verdadeira democracia o Estado político desaparece. O que está correto, considerando-se que o Estado político, como constituição, deixa de valer como o todo. ${ }^{24}$

O que é dizer que na democracia verdadeira a política, ainda que propriamente não desapareça, transforma-se numa "forma particularizada" de seu modo de existência. Forma, é necessário acrescentar, de caráter puramente comissárial e instrumental, insuscetível de autonomizar-se para, de fora, vir a expressar a unidade do todo social. A efetividade da democracia nesse sentido radical e absoluto depende essencialmente, porém, da supressão da diferença entre ordem política e sociedade civil, assim como da divisão interna de cada indivíduo entre seu ser cidadão e sua identidade social concreta ${ }^{25}$. Isto ocorrerá, explica Marx

23 Ênfase, adicionada.

${ }^{24}$ Id., p. 50-51.

25 Em A questão judaica, Marx apresenta o mesmo ponto valendo-se um outro par conceitual, observando que até mesmo nas formas republicanas de organização do poder os indivíduos levam uma vida dupla: terrrestre e celeste ao mesmto tempo. É o que explica o texto seguinte: "Onde o Estado político alcançou seu verdadeiro desenvolvimento o homem - não somente em pensamento, mas na realidade, na vida - leva uma vida dupla, uma vida celeste e uma vida terrena: uma vida na comunidade política, em que ele se considera como um ser coletivo e uma vida na sociedade civil, em que ele age como indivíduo privado, considera os outros homens como meios, degrada-se a si próprio fazendo-se ele próprio meio e convertendo-se em joguete de poderes estranhos a si." Texto citado de acordo com a tradução francesa de M. Rubel, inclusa em K. Marx, Oeuvres III: Philosophie, Paris: Gallimard, Bibliothèque de la Pléiade, 1982, p. 356. 
... quando o homem individual, real, tiver recuperado em si mesmo o cidadão abstrato e quando se tiver tornado, ele, o homem individual, um ser genérico em sua vida empírica, em seu trabalho individual, em suas relações individuais; quando o homem tiver reconhecido e organizado suas forças próprias como forças sociais e não mais apartar de si o poder social na forma do poder político; somente então terá sido realizada a emancipação humana. ${ }^{26}$

O mais problemático nessa tese não está somente nas dificuldades empíricas de superação da distância que separa os indivíduos humanos da vida social integral, nem nos traços psicológicos de natureza individualista, auto referida e egoísta que Hobbes insiste serem próprios dos seres humanos, mas está em que a capacidade de autoreferência dos seres humanos e a liberdade que lhe é correlata fazem com que cada indivíduo seja, metafisicamente, um ponto de origem para a identificação de interesses particulares, para formulação de um projeto de vida próprio, assim como um juiz das condições contextuais em que desdobra sua vida. Além disso, há outra dificuldade, também de princípio, que se liga a esta e que deriva de que, sendo a sociedade formada por uma multidão de indivíduos portadores dos traços característicos que acabam de ser mencionados, sua unidade não pode ser formada horizontalmente, mediante a formação de um nós capaz de falar unissonamente e de, natural e espontaneamente, fazer una a ação de muito homens, para usar a linguagem de Hobbes.

Os clássicos da filosofia política, cada um a sua maneira, insistiram repetidamente nesse ponto e sustentaram sempre a diferença entre o indivíduo considerado em sua singularidade pessoal e privada e sua condição de cidadão. Hobbes trata aprofundadamente dessa questão quanto ao extremar os traços constitutivamente próprios dos coletivos humanos dos que o são dos animais ditos políticos, pondera que enquanto os homens disputam honra e precedência, tendo entre si ódio e inveja, origem da sedição e da guerra, os animais não; além disso acrescenta que abelhas e formigas não veem defeitos, não distinguem dano e injúria, seu "apetite natural" fazendo com que "elas desejem todas um bem comum que não se diferencia do bem particular". ${ }^{27}$ Samuel Pufendorf, em registro um pouco diferente, ao examinar como se coloca a relação dos indivíduos com a unidade de que fazem parte, insiste igualmente que há uma separação irredutível entre os indivíduos e a unidade política a que pertencem. Para demonstração dessa tese Pufendorf registra, primeiramente que há uma assimetria irredutível entre o estatuto das

${ }^{26}$ Id., p. 373.

27 V. Do cidadão, trad. de R. Janine Ribeiro, Martins Fontes, 1992, p. 107-108. 
diferenças internas encontráveis em duas ordens de propriedades relacionais que são próprias dos indivíduos humanos. No âmbito da primeira dessas ordens de relações os indivíduos humanos podem assumir simultaneamente diferentes papéis sociais, de sorte que uma mesma pessoa pode ser "pai, filho, marido, genro, sogro, comerciante, etc." sem que a variação desses diferentes papéis encontre bloqueios de princípio, pois os compromissos que um indivíduo contrair no exercício de cada um desses papéis são, primariamente, contraídos consigo próprio e neste sentido, diz o filósofo, convenções imaginárias. Já o papel de cidadão em uma comunidade - que constitui a segunda ordem de propriedades relacionais distinguidas pelo filósofo - não é constituído por funções e compromissos que assumimos primeiramente por nós mesmos e com relação a nós próprios; não é, portanto, "uma maneira de considerar diversamente as mesmas pessoas", mas, muito diferentemente, é uma relação entre "pessoas realmente distintas [...] as quais têm cada uma vontades diversas e ações diversas" e isso assim mesmo quando a forma do Estado for democrática, pois, diz-nos Pufendorf:

o que cada cidadão quer, o Povo nem sempre o quer. O que cada cidadão faz não é, por isso, considerado como feito pelo Povo e, ao contrário, o que o Povo faz não é tomado como feito por cada cidadão. [...]. ${ }^{28}$

Mesmo Rousseau, para quem o contrato social "produz um corpo moral e coletivo que recebe por esse mesmo ato sua unidade, seu eu comum" ${ }^{29}$ do qual a vontade geral é o exercício, não por isso desconhece ou menoscaba as diferenças entre o homem e o cidadão, entre a pessoa individual e física que cada um é a pessoa moral e coletiva que é o soberano. Ademais disso, Rousseau assinala finamente a diferença entre a unicidade da relação do soberano com os súditos e as duas e diversas relações em que cada indivíduo se encontra vis-à-vis ao soberano. A letra de Rousseau explica melhor esse complexo de relações do que a minha glosa poderia fazê-lo e é, pois, a ela que convém que nos remetamos:

Cumpre observar [...] que a deliberação pública, que pode obrigar todos os súditos para com o soberano, por causa das duas diferentes relações segundo as quais cada deles um é considerado, não pode, pela razão contrária, obrigar o Soberano consigo mesmo. [...] Não podendo

${ }_{28}$ Para esta, assim como para as passagens do autor citadas imediatamente antes, ver Samuel Pufendorf, O direito da natureza e das gentes, tradução para o francês de Jean Barbeyrac, citado aqui de acordo com a edição em fac-símile da edição de Bale feita pelo Centro de Filosofia Política e Jurídica da Universidade de Caen, França, 1987, t. II, p. 232-233.

29 V. J.J. Rousseau, O contrato social, I, VI; Porto Alegre: L\&PM, 2007, p. 34; em J.J. Rousseau, Obras, Editora Globo, 1962, p. 28. 
considerar-se senão sob uma e mesma relação, ele encontra-se no caso de um particular que contrata consigo mesmo.[...] Contudo, o mesmo não acontece com os súditos em relação ao Soberano, a quem, apesar do interesse comum, ninguém responderia por seus compromissos se fosse ele desprovido dos meios de assegurar-se da fidelidade deles. Cada indivíduo [...] pode como homem ter uma vontade particular, contrária ou diversa da vontade geral que tem como cidadão. Seu interesse particular pode lhe falar muito diferente do interesse comum. Sua existência, absoluta e naturalmente independente, pode levá-lo a considerar o que deve à causa comum como uma contribuição gratuita, cuja perda prejudicará menos aos outros, do que o cumprimento a si próprio. Considerando a pessoa moral que constitui o estado como um ente de razão [...], ele desfrutará dos direitos do cidadão sem querer desempenhar os deveres do súdito $[\ldots] .^{30}$

Assim, seja por considerar, como Hobbes, que o concurso em um agir comum duradouro e estabilizado é incompatível com o modo de ser dos indivíduos humanos considerados coletivamente; seja porque, como nos casos de Pufendorf e Rousseau, entendia-se que, mesmo quando o soberano é formado pela convergência das vontades individuais, a separação da pessoa pública das pessoas privadas é inevitável e insuprimível, a verdade é que para os clássicos da filosofia política as ideias e/ou ideais marxistas de que na democracia o homem individual tornar-se-á um ser genérico em sua vida empírica e de que nela o poder social não fará do poder político uma forma de apartar-se de si mesmo não poderiam ser consideradas senão como uma ilusão.

Isto quer dizer, para retomar os termos de Marx de que nos valemos acima, que é inexorável admitir, contra sua postulação, que a monarquia é sim a verdade da democracia, ou, como talvez seja mais preciso dizer, que, contrariamente ao sustentado no Manuscrito de Kreuznach, são simétricas as relações entre (i) ser a democracia a verdade da monarquia e (ii) ser a monarquia a verdade da democracia.

Ora, esse registro, ao mesmo tempo em que nos devolve imediatamente à identidade e representação como componentes do que estou propondo denominar a tópica política, mostra como esta segunda coordenada corta a primeira, a formada por unidade e divisão, como se se constituísse na abcissa desta última, muito embora não pareça que coordenadas cartesianas sejam uma boa maneira de representar graficamente o espaço de variações políticas formais a que estou propondo denominar de tópica política.

$\mathrm{O}$ que estou querendo dizer é que se a unidade de um conjunto político é algo inteiramente diverso das interações entre os indivíduos

30 Id,, p. 37. (na ed. da Globo, p. 29-30). 
que integram uma multidão e se ela, assim, implica necessariamente a dissociação da esfera público-estatal das pessoas privadas, então se torna forçoso concluir que a formação da unidade política é necessariamente dependente da instituição de uma instância representativa capaz de falar e agir como um sujeito, isto é, na terminologia de Hobbes, de uma entidade constituída como uma pessoa, a qual, unicamente, pode fazer uma e una a ação de muitos homens. ${ }^{31} \mathrm{Ou}$, nos termos de Rousseau, como um "corpo moral e coletivo" cujo estatuto é o de um eu comum, dotado de vida e vontade próprias. Na formulação de Hobbes isso implica reconhecer que:

Uma multidão de homens é transformada em uma pessoa quando é representada por um só homem ou pessoa, de maneira a que tal seja feito com o consentimento de cada um dos que constituem essa multidão. Porque é a unidade do representante, e não a unidade do representado, que faz que a pessoa seja uma. E é o representante o portador da pessoa, e só de uma pessoa. Esta é a única maneira como é possível entender a unidade de uma multidão. ${ }^{32}$

No entanto seria um equívoco tomar a representação como como sendo um componente autônomo e fechado em si mesmo dentro do espaço político, pois se fosse assim, como demonstra a objeção de Marx apresentada acima, o príncipe, mesmo sem o povo, poderia ser considerado como um Estado independente. Isto quer dizer que o conceito de representação política precisa ser entendido como o polo de um eixo em cuja outra extremidade se encontra o que Carl Schmitt chamou de identidade, tese que, uma vez transposta para a terminologia do Manuscrito de Kreuznach, quer dizer que democracia e monarquia são os pontos extremos de um mesmo eixo de determinação política. Para elucidar melhor esta questão convém, no entanto, que consideremos o modo como Schmitt introduz e determina os conceitos de identidade e

${ }_{31}$ No cap. V do De Cive o argumento hobbesiano é exposto sinteticamente. Com efeito, ali, depois de notar, no inciso 6, que "nos tópicos que dizem respeito [...] à paz e a autodefesa" é preciso que haja "tão somente uma vontade de todos os homens" e que isso "não se pode fazer a menos que cada um submeta sua vontade a de algum outro (seja este um só ou um Conselho) que tudo o que for a vontade deste, naquelas coisas que são necessárias para a paz comum seja havido como sendo a vontade de todos em geral, e de cada um em particular", Hobbes precisa, no inciso 7 que "isso é a união" e acrescenta, no inciso 9, que "a união assim feita diz-se uma cidade, ou uma sociedade civil, ou ainda uma pessoa civil: pois quando de todos os homens há uma só vontade, esta deve ser considerada como uma pessoa, e pela palavra uma deve ser conhecida e distinguir-se de todos os particulares, por ter ela seus próprios direitos e propriedades. Por isso, nenhum cidadão isolado, nem todos eles reunidos (se excetuarmos aquele cuja vontade aparece pela vontade de todos), deve ser considerado como sendo a cidade." Ob. cit., p. 108-109.

32 Leviatã, ed. cit., p. 102. 
representação no § 17 de sua Teoria da Constituição, em um apartado intitulado justamente Os dois princípios político-formais: identidade e representação.

O conceito de identidade, Schmitt o introduz vinculando-o ao conceito de povo e sustentando que se deve entendê-lo como uma propriedade, se assim posso dizer, de povo no sentido politico da expressão, por oposição "à realidade natural de qualquer grupo humano que viva em comunidade." ${ }^{3}$. O texto apresenta a tese nos termos seguintes:

Este princípio da identidade consigo mesmo do povo existente em um dado momento está baseado em que não há Estado sem povo e que, assim, um povo deve existir sempre como uma grandeza efetiva. O princípio oposto parte da ideia de que a identidade política do povo nunca pode estar presente como uma identidade real, por isso devendo sempre ser representada pessoalmente por homens. ${ }^{34}$

Em seguida, contudo, Schmitt precisa sua tese dizendo:

Na realidade da vida política não há um Estado que possa renunciar a todos os elementos estruturais do princípio da identidade, assim como tampouco há algum que possa renunciar a todos os elementos estruturais da representação. ${ }^{35}$

O texto continua então esclarecendo o estatuto, creio que se pode dizer lógico-metafísico, do designado pelo segundo par de conceitos da tópica política asseverando:

Inclusive ali onde se tenta realizar uma identidade absoluta, seguem sendo indispensáveis elementos e métodos da representação, assim como, inversamente, é impossível uma representação sem uma ideia de identidade. Ambas essas possibilidades, identidade e representação, não se excluem, e não são mais do que pontos de orientação contrapostos para conformação concreta da unidade política. Um ou outro predomina em cada Estado, mas ambos se encontram na existência política de um povo. ${ }^{36}$

É fundamental entender, porém, que esses polos, ou como diz o texto que acabamos de citar, esses pontos de orientação contrapostos, não devem ser vistos como meras referências conceituais que permitem situar em um gradiente comparativo monarquias absolutas e exemplos

33 Id., 243.

34 Ob. cit., § 16, II, p. 237.

35 Id. ib.

36 Id., p. 238. 
de democracia direta. Se fosse assim o estatuto de tais termos seria o de meros instrumentos conceituais para emprego na elaboração de tipologias políticas. Contudo, na visão de Schmitt e no conceito de tópica política cuja apresentação é feita neste texto, esses pontos de vista não são primariamente pontos de vista, nem referências políticas inertes, mas são antes realidades vivas cuja dinâmica se expressa na dependência de toda instância de representação do povo por ela representado. Como se pode perceber sem dificuldade, essa dependência assume ou a forma da legitimação, quando há suficiente identidade entre representante e representado, ou deslegitimação e, no limite, deposição do representante, quando se desvanece completamente a identidade entre esses termos.

Por isso, mesmo se, como diz Schmitt seguindo a Hobbes, "a representação produz a unidade, o produzido é sempre a unidade de um povo em uma situação política" ${ }^{37}$, de onde resulta que a defasagem entre representação e identidade é uma possibilidade sempre aberta, nos casos extremos aparecendo na forma das manifestações de rua de caráter insurrecional, quando, por assim dizer, o povo recupera sua identidade e derruba a representação; nos casos mais benignos, típicos da prática democrática convencional, sua manifestação ocorrendo por meio da alternância no exercício da titularidade do poder soberano em função ou da disputa eleitoral majoritária, ou, nos casos de regimes parlamentaristas, por meio da queda dos gabinetes e da convocação de novas eleições.

\section{Observação final}

Antes de terminar, permitam-me ainda tentar responder a uma pergunta que talvez esteja a obsedar os ouvintes atentos, a que interroga: mas afinal o que se ganha com esse conceito de tópica política que nos está a ser, senão impingido, pelo menos insistentemente proposto?

Ora, a esse questionamento é possível oferecer três respostas, a saber e como segue:

1. pode-se primeiramente dizer que o conceito de tópica política nos dá os recursos analíticos necessários para dissipar a ilusão política, entendida esta como a fantasmagoria contida na visão da possibilidade de construção da política como um sistema de identidade, no qual desapareceria a distinção entre o domínio das relações particulares e privadas e o da vida política e se criaria um mundo no qual, assim, no plano individual, já não levaríamos, como diz Marx, duas vidas: a celeste, em que, enquanto cidadãos, estaríamos dotados de direitos iguais, e

37 V. Id., p. 248. 
a terrestre, aquela em que tocamos nossa vida familiar e profissional, ambas sujeitas às diferenciações mais ou menos agudas, mais ou menos azaradas da vida social real;

2. em segundo lugar pode-se sublinhar que com o conceito de tópica política obtém-se um ganho heurístico relevante, na medida em que ele nos faculta discernir o que, no fundo, está em jogo nas disputas políticas e nos processos de legitimação/deslegitimação dos governos, pois estes se revelam então como sendo sempre uma disputa tensionadora do ponto e do grau em que uma instância representativa, o sujeito ou pessoa pública, expressa e é fiel, ou, no limite, não expressa e não é fiel à identidade do povo, entendida essa como a vontade real, ou existencial, como gosta de dizer Schmitt do povo realmente existente, vale dizer: dos cidadãos ativos, que na rua ou por outros meios fazem valer suas críticas, reivindicações e pretensões;

3. em terceiro lugar pode-se ainda arguir que se obtém um ganho puramente teórico no domínio da metapolítica - entendida esta expressão em sentido análogo ao que possui a chamada metaética, a teoria não das posições em ética normativa, mas a que trata do estatuto dos conceitos, dos juízos e da ontologia das realidades morais - pois a tópica política nos mostra, ontologicamente, se assim posso dizer, (i) que não há entidade política nem sem unidade, nem sem divisão social; (ii) que a unidade só pode ser construída por meio da representação e no eixo que liga esta última à identidade do povo e ainda, (iii) que identidade e representação - divisão e unidade são os nomes que se deve dar às linhas cruzadas ao longo das quais variam os estados em que se pode formalmente encontrar uma comunidade politicamente organizada no desdobrar-se dos acontecimentos e vicissitudes que constituem sua história concreta.

\section{Referências}

ALEXANDER OF APHRODISIAS. On Aristotle Topics 1. New York: Bloomsbury Academics, 2014.

ARISTÓTELES. Política. Brasília: Editora da Universidade de Brasília, 1985.

ARISTÓTELES. Tópicos. Lisboa: Centro de Filosofia da Universidade de Lisboa e Imprensa Nacional - Casa da Moeda, 2007.

BECKER, Carl L. The Declaration of Independence. New York: Random House - A Vintage Book, 1958.

CASTORIADIS, Cornelius. L'institution imaginaire de la société. Paris: Seuil, 1975.

HEGEL, G. W. F. "Linhas Fundamentais da Filosofia do Direito ou Direito Natural e Ciência do Estado no traçado fundamental", O Estado, IFCH/UNICAMP, 1998.

. Enciclopédia das Ciências Filosóficas em Compêndio. São Paulo: Loyola, 1995.

HOBBES, Thomas. Leviatã. São Paulo: Abril Cultural, 1974. 
HOBBES, Thomas. Do cidadão. [São Paulo]: Martins Fontes, 1992.

KANT, Immanuel. Crítica da Razão Pura. Lisboa: Fundação Calouste Gulbenkian, 1989.

LEFORT, Claude; GAUCHET, Marcel. "Sur la démocratie: le politique et l'institution do social", Textures, 2-3 (1971).

MARX, Karl. O Capital, L. III, in Oeuvres, Économie II, Paris: Gallimard, Bibliothèque de la Pléiade, 1968.

. A questão judaica, in Oeuvres III: Philosophie, Paris: Gallimard, Bibliothèque de la Pléiade, 1982.

. Crítica da filosofia do direito de Hegel, São Paulo: Boitempo Editorial, 2005.

MARX, Karl; ENGELS, Friedrich. Manifesto Comunista. São Paulo: Boitempo Editorial, 1998.

MERLEAU-PONTY, Maurice. Resumés de Cours - 1952-1960. Paris: Gallimard, 1968.

MEYER, Pauline. American Scripture - Making the Declaration of Independence, New York: Alfred A. Knopf, 1997.

PUFENDORF, Samuel. Le droit de la nature et des gens, tradução de Jean Barbeyrac, edition de Bâle, 1732, publicada em fac simile pelo Centre de philosophie polítique et juridique de l'Université de Caen, France, 1987.

ROUSSEAU, J. J. O contrato social. Porto Alegre: L\&PM, 2007.

. Obras, II. Porto Alegre: Editora Globo, 1962.

SCHMITT, Carl. Teoria da Constituição. Mexico, DF: Editora Nacional, 1981.

TOMAS DE AQUINO. Sententia libri Politicorum, Livro 2. Disponível em: <http:// www.corpusthomisticum.org/cpo.html>.

TORRES, João Carlos Brum. "Actes fondateurs au domaine politique", Les Cahiers de Fontenay, E.N.S. Fontenay/Saint-Cloud, 67-68 (septembre 1992).

\section{Endereço postal:}

Universidade de Caxias do Sul - Programa de Pós-Graduação em Filosofia

Rua Francisco Getúlio Vargas, 1130, Bloco E, sala 306

Caxias do Sul, RS, Brasil

Data de recebimento: 07/01/2015

Data de aceite: 10/01/2015 